
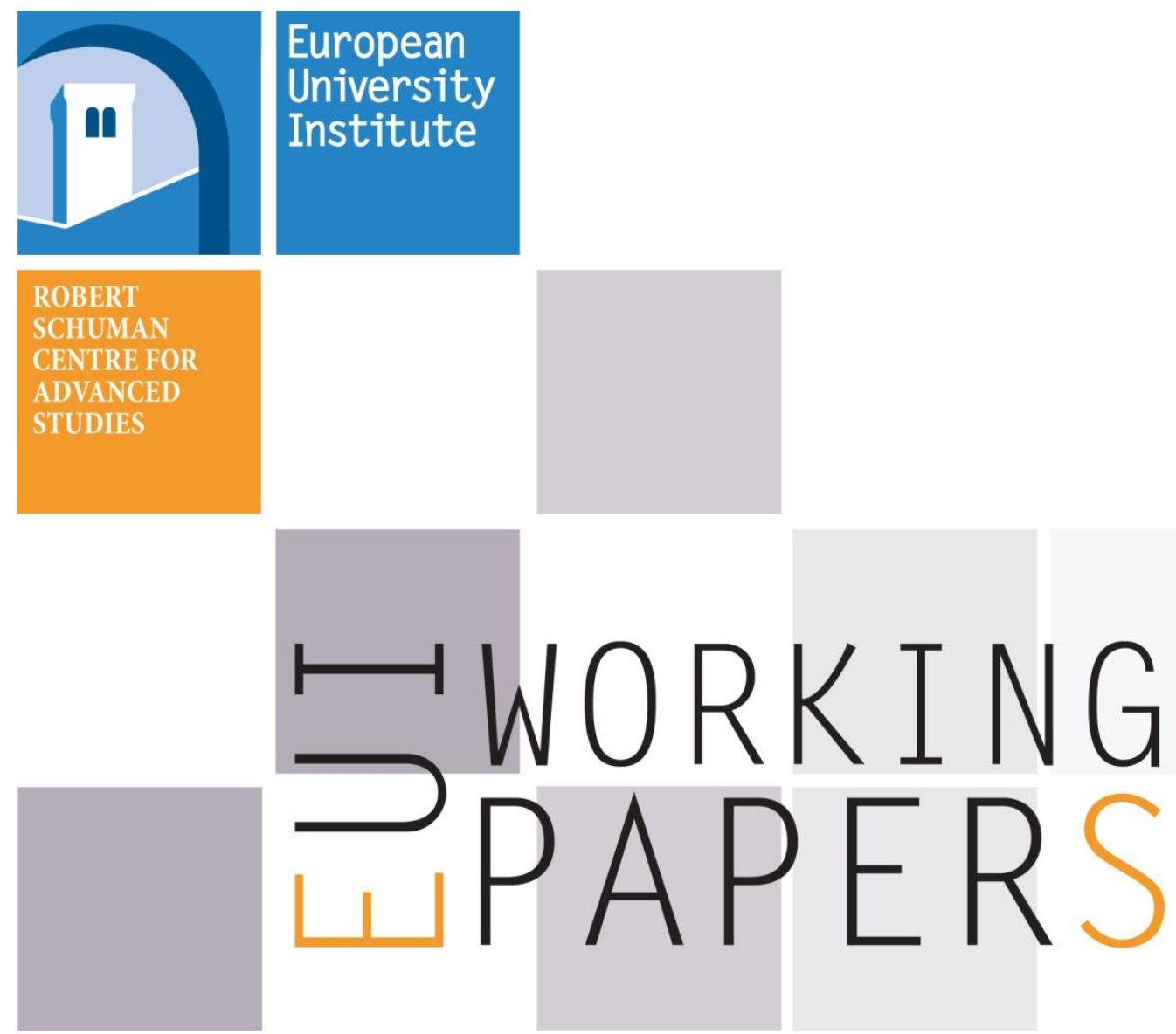

RSCAS 2013/39

Robert Schuman Centre for Advanced Studies Florence School of Regulation

A post-2020 EU energy technology policy: Revisiting the Strategic Energy Technology Plan

Sophia Ruester, Sebastian Schwenen, Matthias Finger and Jean-Michel Glachant 

European University Institute

Robert Schuman Centre for Advanced Studies

Florence School of Regulation

\section{A post-2020 EU energy technology policy: \\ Revisiting the Strategic Energy Technology Plan}

Sophia Ruester, Sebastian Schwenen, Matthias Finger and Jean-Michel Glachant

EUI Working Paper RSCAS 2013/39 
This text may be downloaded only for personal research purposes. Additional reproduction for other purposes, whether in hard copies or electronically, requires the consent of the author(s), editor(s). If cited or quoted, reference should be made to the full name of the author(s), editor(s), the title, the working paper, or other series, the year and the publisher.

ISSN 1028-3625

(C) Sophia Ruester, Sebastian Schwenen, Matthias Finger and Jean-Michel Glachant, 2013

Printed in Italy, June 2013

European University Institute

Badia Fiesolana

I - 50014 San Domenico di Fiesole (FI)

Italy

www.eui.eu/RSCAS/Publications/

www.eui.eu

cadmus.eui.eu 


\section{Robert Schuman Centre for Advanced Studies}

The Robert Schuman Centre for Advanced Studies (RSCAS), created in 1992 and directed by Stefano Bartolini since September 2006, aims to develop inter-disciplinary and comparative research and to promote work on the major issues facing the process of integration and European society.

The Centre is home to a large post-doctoral programme and hosts major research programmes and projects, and a range of working groups and ad hoc initiatives. The research agenda is organised around a set of core themes and is continuously evolving, reflecting the changing agenda of European integration and the expanding membership of the European Union.

Details of the research of the Centre can be found on:

http://www.eui.eu/RSCAS/Research/

Research publications take the form of Working Papers, Policy Papers, Distinguished Lectures and books. Most of these are also available on the RSCAS website:

http://www.eui.eu/RSCAS/Publications/

The EUI and the RSCAS are not responsible for the opinion expressed by the author(s).

\section{Florence School of Regulation}

The Florence School of Regulation (FSR) is a partnership between the Robert Schuman Centre for Advanced Studies (RSCAS) at the European University Institute (EUI), the Council of the European Energy Regulators (CEER) and the Independent Regulators Group (IRG). Moreover, as part of the EUI, the FSR works closely with the European Commission.

The objectives of the FSR are to promote informed discussions on key policy issues, through workshops and seminars, to provide state-of-the-art training for practitioners (from European Commission, National Regulators and private companies), to produce analytical and empirical researches about regulated sectors, to network, and to exchange documents and ideas.

At present, its scope is focused on the regulation of Energy (electricity and gas markets), of Communications \& Media, and of Transport.

This series of working papers aims at disseminating the work of scholars and practitioners on current regulatory issues.

\section{For further information}

Florence School of Regulation

Robert Schuman Centre for Advanced Studies

European University Institute

Via Boccaccio, 151

I-50133 Firenze

Tel.: +39055 4685751

Fax: +39055 4685755

E-mail: fsr@eui.eu

http://www.eui.eu/RSCAS/ProfessionalDevelopment/FSR/ 



\begin{abstract}
With the European Strategic Energy Technology Plan (SET Plan) expiring in 2020, the EU needs to revisit its energy technology policy for the post-2020 horizon and to establish a policy framework that fosters the achievement of ambitious EU commitments for decarbonization by 2050. We discuss options for a post-2020 EU energy technology policy, taking account of uncertain technology developments and uncertain carbon prices. We propose a revised SET Plan that enables policy makers to be pro-active in pushing innovation in promising technologies, no matter what policy context will be realized in the future. In particular, we find that a revised SET Plan is needed to support EU market actors who face market failures with respect to financing innovation within a highly competitive global market for energy technologies. An extension of the current SET Plan and corresponding technology push policies is insufficient, as this does not allow policymakers to provide adequate support, especially in a policy context with low or zero carbon prices.
\end{abstract}

\title{
Keywords
}

European energy policy 2050, Energy technology policy, SET Plan 



\section{Motivation*}

The overarching long-term EU climate policy goal is to reduce greenhouse gas (GHG) emissions within the EU by at least $80 \%$ below 1990 levels by 2050. European policymakers are facing substantial challenges in achieving this goal. Current policy initiatives, such as the SET Plan, are running out in 2020. Global competitive pressure on European industries, along with the European sovereign-debt crises, heavily constrain existing budgets and public acceptance for climate and clean energy policies. The recently by the European Parliament rejected proposal on the backloading of emission rights well illustrates these constraints. Nonetheless, clear-cut policies for 2050 are needed, something also stressed in the recent EU communication on energy technologies and innovation (EC, 2013).

Much effort has already been spent by the European Commission but also by market actors on the evaluation and impact analyses of different policies promoting different (to a high degree decarbonized) technology mixes, for example in EC (2011), Eurelectric (2011), or IEA (2012). These analyses suggest that much of the success of EU climate policy depends upon low-carbon energy technologies and their viable deployment in European electricity markets. However, which different policies actually can steer electricity markets to one or the other future technology mix remains an open question. For this reason, this article develops and discusses different policy paths for a post2020 EU energy technology policy. We evaluate these different policy paths and show what technology mixes are more likely to take place, given one or the other path. We also propose a design for a renewed post-2020 SET Plan that can - under any policy path realized - be an effective tool for policymakers in steering innovation and pushing low-carbon energy technologies towards 2050.

The paper is structured as follows. Section 2 demonstrates the need for a European energy technology policy and critically assesses the effectiveness of currently implemented policy measures. Section 3 proposes possible paths for a post-2020 policy, which are then evaluated along several criteria in Section 4. We finally discuss policy implications for a revised SET Plan that should not exclude the possibility to act within any future context in Section 5. Section 6 concludes.

\section{Need to revisit existing policies}

In what follows, we demonstrate the need for a European energy technology policy and critically assess the effectiveness of currently implemented policy measures.

\subsection{Why energy technology policy is needed}

Energy technology policy comprises all measures that aim at promoting a selected set of energy technologies from early research to market deployment. Such a promotion typically leads to many overlaps with other policy areas. As different technologies show different environmental impact, energy technology policy also relates to environmental policy. When selected technologies and projects are then supported at the basic research stage, intersections with science and innovation policy arise. When certain technology sectors are promoted on the world market, technology policy influences industrial or even trade policy. In this article, we focus on energy technology policy in a narrow sense, in which policymakers can choose what technologies to promote, by what means, to which extent, and for which period of time.

This research has been conducted within the project THINK (http://think.eui.eu) which has been funded by the EU's 7th Framework Programme. We thank Serge Galant, François Lévêque, Wladyslaw Mielczarski, Ignacio Pérez-Arriaga, as well as participants at the DG ENER - THINK Workshop held in Brussels on 14th November 2012 for helpful comments and suggestions. While as a part of the THINK project DG ENER provided helpful feedback, the expressed views are solely those of the authors. The usual disclaimer applies. 
That from an economic point of view policy intervention and the existence of energy technology policy as such is justified, is commonly accepted in the economic literature - technology policy can be motivated by market externalities and imperfections on the one hand, or by strategic industry and trade policy concerns on the other:

Environmental externalities: The emission of GHGs involves negative externalities. Emitters cause climate change and, thus, impose costs on the whole population and future generations. The reduction of emissions consequently is a global public good and unless such reduction is adequately rewarded, or emissions properly charged, the incentive to develop and deploy low-carbon technologies will be too low. From a global perspective, a common, comprehensive, global carbon price would be the economically efficient instrument, inducing emission reductions wherever they are cheapest and minimizing abatement costs across all sectors (Stern, 2006). Hence, technology policy may implement incentives in favor of deploying low-carbon technologies.

Innovation externalities: Most low-carbon technologies are not yet competitive or even not technologically proven. All fundamental and a part of applied knowledge gained from research activities is a public good, because without a very restrictive access regime, innovating firms cannot fully appropriate the returns to their RD\&D activities due to existing spillover effects. Jaffe (1996) gives an excellent account of various market and technological spillovers arising from private innovation activities. Martin and Scott (2000) and Foxon (2003) discuss the resulting market failures of low-carbon innovation. In this context, technology policy may implement incentives to innovate despite spillover effects.

Capital market imperfections: Capital markets suffer from information asymmetries among innovators, investors and policy makers. Moreover, innovations in clean energy technologies often pair high capital requirements with substantial economic, technical and regulatory uncertainties. As a result, many investors are constrained in equity as well as debt capital. Hyytinen and Toivanen (2005) present evidence that especially small and new firms suffer from higher cost of capital than their larger, incumbent competitors. Technology policy can include tools, such as low interest loans, that ease funding whenever the net benefits of respective projects are positive but financial agents reject finance.

Increasing global competition: The challenge Europe is facing today is "to remain at the forefront of the booming international market for energy technology" (EC, 2010, p. 15). If decarbonization has no alternative, but real potential gains from decreasing electricity generation and supply costs only occur in the longer-run, growth effects stemming from the competitive production and profitable trade of low-carbon technologies on the world market are key to enhance growth in the shorter-term. Hence, technology policy can be motivated by strategically pushing certain low-carbon technologies on the world market.

\subsection{Effectiveness of currently implemented policies}

The effectiveness of existing policies can be assessed in the context of the four above initial reasons for policy intervention. Especially regarding environmental and innovation externalities and also financial measures to account for capital market imperfections, we find that current measures are limited in their effectiveness and call for improvements for post-2020 policies.

The major policy tool to account for environmental externalities is the EU-wide emission trading scheme (EU ETS), introduced in 2003. The 2009 climate and energy policy package strengthened legislation and extends the coverage of the EU ETS substantially. ${ }^{1}$ However, the EU ETS does not yet

1 Directive 2009/29/EC considers a single EU-wide cap on emission allowances from 2013 on, the stepwise replacement of a free allocation by auctioning, and an enlarged list of activities and GHGs covered. Decision 2010/634/EU sets the total 
deliver an adequate price signal, see Ellerman et al. (2010), Schmidt et al. (2012) or Martin et al. (2012). Prices are neither at a sufficiently high level nor reliable, but instead are argued to be too low and far from being predictable in the long-term. As a consequence, the UK Government, for instance, unilaterally introduced a price floor of GBP 16/ton in 2011 (which follows a linear path up to GBP 30/ton in 2020). The European Parliament's rejection of the backloading proposal decreases the chances that sufficiently tight caps will be introduced soon, and it is open whether different European Member States might follow the British example as a result of this decision.

Regarding innovation externalities, EU policies mainly aim at directly or indirectly promoting lowcarbon technologies. Indirect promotion mostly comes in the form of national support schemes for low-carbon technologies. Directive 2009/28/EC sets binding national targets for the share of renewable energy sources (RES) in gross final energy consumption by 2020. Member States have full autonomy in the choice of policy measures and have already implemented a wide set of instruments (Ecofys et al., 2011; Jacobsson et al., 2009; Ragwitz et al., 2011 and references therein). Kitzing et al. (2012) find indications for a bottom-up convergence of policy choice. Indeed, the Commission expressed lately that "a greater convergence of national support schemes to facilitate trade and move towards a more pan-European approach to development of renewable energy sources must be pursued" (EC, 2011b, p. 11).

Directly promoting low-carbon technologies comes in the form of EU and national technology push policies. For this sake, the EU's Strategic Energy Technology Plan (SET Plan) has been adopted in 2008 as the so called 'technology pillar' of the EU energy and climate policy. Its implementation started with the establishment of the European Industrial Initiatives which bring together industry, the research community, Member States and the Commission. Within these Initiatives, strategic objectives have been formulated based on Technology Roadmaps that identify priority actions for the decade from 2010 to 2020. More specific Implementation Plans, containing more detailed descriptions of proposed RD\&D activities, as well as suggestions about potential funding sources, are developed regularly for three-year periods.

However, the SET Plan, in its current formulation, i.e., with the objective to "support the achievement of 2020 goals", has a limited time horizon. In addition, all planning and priority setting is conducted within the Industrial Initiatives. In other words, it is done for solar PV/CSP among stakeholders from the solar industry, for wind among stakeholders from the wind industry, and similarly for CCS, nuclear, et cetera. Hence, it becomes obvious that this current policy does not necessarily support an optimal (cost-efficient) portfolio of low-carbon technologies, i.e., decarbonization at least cost.

When it comes to financing technology push in the form of direct support to innovation, the 'Carvalho Report' (European Parliament, 2010) illustrates that the EU Framework Programmes have been powerful mechanisms for catalyzing and accelerating RD\&D. Nevertheless, many stakeholders criticize that FP7 is "despite the improvements made in relation to FP6, still characterized by excessive bureaucracy [...] and undue delays" (p. 4). Current practice also shows that subsidies in the form of grants and contracts - the most attractive form of support from the innovators' perspective, but also the most expensive one for the public sector - are, by far, the preferred policy instruments to fund clean energy innovation of any type, see Olmos et al. (2012). Recent initiatives, however, go into the right direction. Compared to former Framework Programmes, Horizon 2020 aims to simplify administrative procedures, from which especially small innovators should benefit. Furthermore, the program will - besides grants - also include output-based funding, such as technology prizes, and loan and equity financing are expected to play a greater role, too. And also the implementation of an $E U$ Patenting System in 2014 will substantially decrease cost for innovators.

(Contd.)

EU-wide amount of allowances at 2,039mn for 2013. The cap will decrease by $1.74 \%$ per year, with this factor scheduled to be reviewed by 2020 . 
As for policy intervention regarding capital market imperfections and the external financing of innovation, the economic and financial crises had severe consequences on the ability to mobilize private (both company internal and external) and especially public funds. As a consequence of the recent developments in credit markets and regulatory measures that have been implemented accordingly, ${ }^{2}$ it has become increasingly difficult to access long-term financing, especially for projects with a high investment volume, as is the case for many energy innovation and demonstration projects. In addition, the current period of austerity has imposed tight fiscal constraints on national budgets and forces governments to re-think fiscal policies and to reconsider what their tax payers can afford in terms of low-carbon energy technology support. Different countries, such as Greece, France or the UK, have cut renewable subsidies substantially (Gilder-Cooke, 2012).

A first policy response to these challenges has been the European Energy Programme for Recovery, a EUR 4bn program set up in 2009. However, given the complexity and magnitude of the crises, much more action is needed to keep low-carbon RD\&D and innovation on track towards 2020 and beyond.

Last, policies related to stimulating the competitiveness of European (technology) companies on the world market have to increasingly recognize third countries that have built strong competitive positions in RD\&D and manufacturing of different low-carbon technologies. European players currently suffer from substantially reduced market shares in e.g. the solar PV or onshore wind turbine sectors. As also highlighted in the most recent Competitiveness Report (EC, 2011c), global competition in this area has become much fiercer. In a recent Communication (EC, 2012), six "Key Enabling Technologies" (e.g., advanced materials or advanced manufacturing technologies) have been identified, which is a first step towards explicitly focusing and prioritizing specific industrial sectors.

Summarizing, we find it at least doubtful that the mix of currently implemented policy measures can deliver cost-efficient decarbonization.

\section{Possible paths for a post-2020 EU energy technology policy}

In order to capture the broad spectrum of policies to achieve decarbonization despite all these challenges, this section first introduces the set of available policy instruments. Using these instruments, we then develop alternative paths for a future EU energy technology policy towards 2050 .

\subsection{Policy Instruments}

Two broad classes of instruments can be used to accelerate innovation, demonstration and deployment of low-carbon technologies. First, market pull instruments mainly address the positive externalities of clean energy production and shall incentivize deployment of and innovation in low-carbon technologies. A general distinction can be made among instruments building on price signals (such as carbon pricing) and instruments incentivizing via the definition of binding quantitative targets (such as the national targets for RES shares in gross final energy consumption by 2020). This basic distinction between price and quantity signals was first studied by Weitzman (1974), who stresses that differences in their outcomes can only be due to asymmetric information between firms and their governing regulatory authorities. Second, technology push mainly targets the correction of positive externalities related to spillover effects during the innovation process. Push can either be directed (such as EEPR

2 Basel III as a global regulatory standard on banking capital adequacy, stress testing and market liquidity, strengthens capital requirements and introduces new regulatory requirements on liquidity and leverage. EU Directive 2009/138/EC codifies and harmonizes EU insurance regulation and amongst others sets standards regarding the amount of capital that insurance companies must hold to reduce the risk of insolvency. 
funds dedicated to support offshore wind and CCS demonstration projects) or, in contrast, can involve technology-neutral support to innovation.

There is a consensus in the energy technology policy literature that market pull alone does not lead to the desired outcomes, see Horbach (2007), Nemet (2009) or Jones and Glachant (2010). A welldesigned policy instead involves pull to deal with the environmental externality, and, at the same time, technology push to deal with the knowledge and spillover externalities. The relative importance of market pull vis-à-vis technology push decreases, as one moves from technologies close to market competitiveness towards highly immature ones, see Grubb (2004). Especially the central stages of the value chain, commercial-scale demonstration and early deployment, involve substantial investment needs accompanied by still non-negligible risks. This "valley of death", where the key challenge is the transition from publicly co-financed to private operations, is discussed in-depth elsewhere, see e.g. Murphy and Edwards (2003) or Weyant (2011).

Policy intervention can be governed by the EU, jointly coordinated among countries, or by individual Member States who seek to intervene mainly on their home market. Challenges accompanying the transition to a low-carbon, high-reliability power system at acceptable social costs, are clearly European. From an institutional perspective, there are shared competences between Member States and the EU regarding the achievement of the European environmental and energy policy goals (Art. 192 and 194, Treaty of the Functioning of the EU), as well as related to actions that ensure the conditions necessary for the competitiveness of the European industry (Art. 173). It is thus necessary to investigate whether there are substantial economic benefits to be gained from EU involvement, but at the same time to set those benefits into relation with the costs of pooling public regulatory power at this highest political level.

Hence, policy paths consist of three elements:

1. Market pull instruments framing the context for technology push by a) creating markets via strong price signals and/or b) providing signals through quantitative targets;

2. Technology push instruments: a) directed technology push and/or b) technology-neutral support to innovation;

3. Governance of these instruments: a) decentralized national action and/or b) centralized, crossnational action with EU involvement.

In the following, we introduce three polar future pathways for an EU energy technology policy. From a reference case, we can depart in two major ways: in line with options for a post-2020 RES policy outlined in a recent Communication on renewable energy (EC, 2012b), it can either be prices or quantitative targets that give the key signals to innovate and invest in clean technologies. Starting from this distinction and different paths of market pull framing the context for energy technology policies, for each case the respective role of the SET Plan is discussed.

\subsection{Policy path 1: Reference path}

The first policy path determines a reference case in which 2020 policies would be extended to 2030 and 2050. This option is based on a mix of incentives coming from carbon pricing and quantitative target setting. As in the current 2020 policy, with both the EU ETS and EU-wide targets for RES and improvements in energy efficiency, along with national energy policies to meet corresponding national targets, a wide set of market pull instruments prevails. For similar reasons as today and discussed in Section 2, the carbon price will only provide a relatively weak investment and innovation signal.

The SET Plan would be further developed and expanded, resulting in at least as much as the current nine Industrial Initiatives that can provide the basis for coordination and research prioritization. Therefore, SET Plan support will continue to be of a rather broad nature and not be unanimously 
focused on and aligned with more specific technology targets. Both, technology-specific push but also competitive funds, coming from EU and national sources, are prevailing as technology push instruments.

Hence, the governance of instruments remains, just as in the 2020 policy, mixed with elements managed at national and cross-national levels and continues a policy of multiple means and actors.

\subsection{Policy path 2: Strong carbon price and focus on price signals}

Starting point for the second policy path is a strong carbon price signal. Here we assume perfectly adjusted ETS and according non-ETS prices that mirror in a single, adequate and reliable carbon price covering most, if not all, GHG emissions. Such a carbon price would then be the major driver of innovation in clean technologies and for decarbonization. Sectoral targets cease after 2020, and from then on, the market will react to the carbon price alone. Additional national support schemes might coexist; however, the strong carbon price will decrease the necessity of ambitious individual Member State actions.

Technology push plays a rather accommodating role to lift promising technologies from R\&D to commercialization and preliminarily would rely on technology-neutral financial support to innovation, and thus, on competition for funds among different technologies and innovation projects. Promising projects at the early stages of such technology developments can obtain additional public funding. After having delivered its initial push, the importance of the SET Plan as an instrument to prioritize among technologies and projects vanishes by 2020 . It will rather function in a 'light' version as a platform for information exchange (on e.g. the status quo of technologies, costs, experience with pilots, etc.) and stakeholder coordination and cooperation. Hence, it will preliminary become a tool that can help potential innovators and investors to take the right decisions and to mobilize private funds.

The governance of instruments will have to be predominantly centralized and administered by the EU since the key instrument in this path would be a strong, EU-wide carbon price. Technology push could potentially be administered and funded by both the EU and Member States with centralized funding programs and individual national funding schemes co-existing. For this policy, there is also a possibility for the EU to generate its own source of income which could be made available to implement such funding methods: parts of the income generated through the auctioning of allowances could be collected centrally and be redistributed for coordinated RD\&D support.

\subsection{Policy path 3: Weak carbon price and sectoral targets}

Starting point for the third policy path is the presence of a very weak carbon price signal. Incentives for innovation and technology deployment here will mainly originate from quantitative sectoral targets, with sectors being understood as specific low-carbon technologies. These targets aim at providing stable signals to industry, consumers and finance sectors as to what technologies will be prioritized on for European technology push. In the updated business-as-usual scenario of policy path 1 , those targets are less focused and support almost the full range of technologies. In this policy path 3 , the technology push will be specific to the most promising technologies. The strong and binding EUlevel and corresponding national targets will be jointly agreed upon by the Member States, taking into account also region-specific technological potentials and cost. Their implementation then will occur under individual governments' responsibility. National action plans provide Member States with a degree of freedom for their own national implementation.

Targets and corresponding funds for technology push will come from an extended SET Plan, which focusses on more narrowly selected technologies. This 'advanced' SET Plan would attempt to find a future proof technology portfolio, and thus, will not only serve as a platform for stakeholder 
coordination, but also provide the basis for planning and priority (as well as target) setting and the determination of an optimal portfolio of low-carbon technologies, as well as for the allocation of public (especially European) funds. Technology-specific, directed financial support will be a key element in the concept of this policy design. Competitive funds for clean technologies might co-exist, but play a minor role.

The governance of policy instruments, hence, will be predominantly decentralized. While the EU has to play a role in administering the ETS and moderating Member States' decisions on sectoral targets, the implementation of this policy mainly relies on decentralized national action. The following table offersa summary of the various above discussed policy paths.

Table 1: Summary of policy paths

\begin{tabular}{|l|c|c|c|}
\cline { 2 - 4 } \multicolumn{1}{c|}{} & $\begin{array}{c}\text { Policy path 2: } \\
\text { Strong carbon price }\end{array}$ & $\begin{array}{c}\text { Policy path 1: } \\
\text { REFERENCE }\end{array}$ & $\begin{array}{c}\text { Policy path 3: } \\
\text { Weak carbon price }\end{array}$ \\
\hline $\begin{array}{l}\text { Market pull (MP) } \\
\text { Key signal through price or } \\
\text { quantitative target? }\end{array}$ & Strong carbon price & Hybrid & Sectoral targets \\
\hline $\begin{array}{l}\text { Technology push (TP) } \\
\text { Directed or technology-neutral? }\end{array}$ & $\begin{array}{c}\text { Predominantly } \\
\text { technology-neutral }\end{array}$ & Hybrid & $\begin{array}{c}\text { Predominantly directed } \\
\text { push }\end{array}$ \\
\hline $\begin{array}{l}\text { Governance of MP and TP } \\
\text { instruments } \\
\text { Centralized or decentralized? }\end{array}$ & $\begin{array}{c}\text { Predominantly } \\
\text { centralized }\end{array}$ & Hybrid & Predominantly \\
decentralized
\end{tabular}

\begin{tabular}{|l|c|c|c|}
\hline SET Plan & Light & BAU & Advanced \\
\hline $\begin{array}{l}\text { Platform for stakeholder } \\
\text { coordination \& cooperation }\end{array}$ & $\mathrm{x}$ & $\mathrm{x}$ & $\mathrm{x}$ \\
\hline $\begin{array}{l}\text { Basis for planning and priority } \\
\text { setting }\end{array}$ & & $\begin{array}{c}\mathrm{x} \\
\text { (within Industrial } \\
\text { Initiatives) }\end{array}$ & $\begin{array}{c}\mathrm{x} \\
\text { (across Industrial } \\
\text { Initiatives) }\end{array}$ \\
\hline $\begin{array}{l}\text { Basis for the allocation of EU } \\
\text { funds }\end{array}$ & $\quad$ (x) & $\mathrm{x}$ \\
\hline Basis for target setting & & & $\mathrm{x}$ \\
\hline
\end{tabular}

\section{Multi-criteria evaluation}

In what follows, we evaluate the presented polar policy paths. The evaluation proceeds along five criteria that all relate to the limitations of the status quo as discussed earlier:

- Climate-effectiveness: Does the policy deliver decarbonization by 2050 ?

- Green growth: Does the policy enable green growth and respond to fierce global competition in green-tech markets?

- Robustness to economic/financial crises and institutional frictions: Is the policy robust with respect to (today's and future) economic/financial crises and institutional frictions?

Since all benefits that increase the effectiveness of future policies come at certain costs, and, in addition, differ regarding potential difficulties related to their implementation, we further add: 
- Cost-efficiency: Does the policy achieve climate and growth goals at lowest costs?

- Implementability: Is the policy politically and institutionally feasible? Which barriers to implementation are expected?

We do not use our findings to globally rank policies, since the absence of an objective procedure for weighting competing criteria restricts the possibilities for a scientifically robust ranking. Instead, the following multi-criteria evaluation is used to elicit trade-offs among alternative policies.

\subsection{Climate effectiveness}

If all GHG emissions are included into a cap-and-trade scheme, as would be the case in a very strict version of policy path 2 , the decarbonization target would be reached by definition. Climate effectiveness will be less predictable for a scheme where part of the emissions are not included into the trading mechanism but are subject to a carbon price in the form of an emission tax. For such pricebased instruments, the aggregate emission reduction quantity will be a response of market players to the tax and, hence, can only be estimated ex-ante. Climate efficiency will also be less predictable for policies 1 and 3, which, besides a relatively weak carbon pricing scheme build on complementary target setting. Policy makers cannot be sure which exact amount of abatement will be induced and a certain under- (or even over-) achievement of the emission reduction target may occur.

Hence, with respect to climate effectiveness, policy path 2 seems to be slightly preferable to paths 1 and 3. However, with such a long time horizon, predictions about the exact outcome in 2050 are hardly possible and the problem will rather lie in achieving cost-efficient abatement, which is discussed below.

\subsection{Green growth}

Besides some very first attempts to identify Key Enabling Technologies, policy path 1 does not present explicit remedies addressing challenges related to the increasing global competition in greentech sectors. National initiatives in general also will not be sufficient because most of the Member States are too small to compete on a global scale with economies such as the US or China. For the second policy path, departing from strong price signals, it would be the industry that should discover promising areas of innovation. On the one hand, there are good arguments to build on market signals and private sector decisions. On the other hand, one could argue that there might be the risk that public support for innovation, that at the same time could foster green growth, might come too late. Being too late also implies missing out potential first mover advantages in globalized markets.

In contrast, policy 3 allows public authorities to support technologies already in very early stages of the innovation chain, and governments or the EU can explicitly target those industries where one can build or keep industrial leadership. However, this strategy faces several risks. First, 'wrong winning technologies' might be targeted. There is a widespread concern about the potential for policy makers to efficiently direct technological change in a welfare-improving manner, see Johnstone and Hascic (2010). Such winner-picking also might discourage potential innovators to explore new least-cost innovation. A second risk concerns potential institutional and political lock-in in the allocation of funds. Once technologies are chosen, funded and there are rents to distribute, interested stakeholders might make it impossible in the political processes to shift funding to other technologies or projects.

Despite these risks inherent to policy 3 , the strong reliance on technology push nevertheless offers a huge potential to stimulate green growth. Technology push can also be used to push innovation and growth within the EU, and even in selected Member States or regions. Under the EU ETS, in contrast, European consumers incentivize innovation on the world market by also making it more profitable to 
invest in green technologies outside the EU and then to sell products to companies operating under the emission trading scheme.

\subsection{Robustness to economic and financial crises and institutional frictions}

An energy technology policy towards 2050 inherently concerns with long-run economic developments. Therefore, such a policy should be robust to scarce financing caused by current (and possible future) financial crises and be consistent with future developments of the EU institutional system.

A first relevant aspect here is the ability to mobilize funds within each policy path. The current situation does not create sufficient certainty for investors. As the current crisis shows, and GilderCooke (2012) discusses, several highly indebted countries stop supporting RES. Investors might shy away from these countries for a considerable future time. Stakeholders furthermore argue that carbon prices are far too low and volatile to yield stable investment signals. Policy path 3 with strong technology targets and strong accommodating technology push, in contrast, can not only provide stable investment signals, but can also be used within a stimulus package in times of crisis. The decentralized governance moreover allows for tailored national solutions, which can react to differing national needs, e.g. countries can choose their abatement channels and shift abatement costs across sectors.

Second, one has to ask how the governance of these instruments can be deterred by potential EU institutional difficulties, such as the current debt crisis, that leaves different Member States with different potentials in sticking to committed long-run climate goals. The impact will depend on the (future) degree of heterogeneity among Member States. A higher degree of heterogeneity will speak in favor of decentralized solutions and hence for policies closer to paths 1 or 3 for similar reasons as discussed above.

\subsection{Cost-efficiency}

Given the fixed target of decarbonization, cost-efficiency implies cost minimization. Abatement costs will be minimized by using the various abatement channels available. Obviously, abatement costs differ across sectors, firms and households, and hence, it cannot be cost-efficient if all actors simply had to abate by the same percentage points of their historical emissions. Instead, one common price on emissions minimizes abatement costs, as was already pointed out by Baumol and Oates (1971). This directly illustrates cost advantages for policy path 2 . $^{3}$

Whether policy path 3 is preferred over the reference case will depend upon the exact specification of technology priorities. For both options one may doubt whether policy makers possess the required information to define targets that imply that the costs of such technology mixes are just in line with the benefits of abatement. At the same time, technology mandates do not engage all abatement channels but likely will miss out promising, cost-efficient abatement opportunities.

\subsection{Implementability}

Implementability and subsidiarity compatibility of policies also need to be considered, taking account of the legal and institutional context. For the reference case, this is given. There are shared

3 As Goulder and Parry (2008) emphasize, with high monitoring costs associated to emission pricing, its benefits disappear, what also can reduce trading levels and increase abatement costs, see Stavins (1995). The inability to perfectly monitor policy implementation might also explain suspected over-allocation of permits during the initial phase of the EU ETS, as studied in Ellerman and Buchner (2008). 
responsibilities between the EU and Member States fully in line with the shared competences as defined in the Treaty of the Functioning of the EU. Centrally coordinated instruments complement national action as already established. Various stakeholders have the opportunity to use platforms such as the Industrial Initiatives to cooperate, and the within-sector approach of planning and priority setting of the current type of SET Plan avoids that individual sectors feel disadvantaged. Moreover, past success in bringing stakeholders together, being pioneer in certain technological areas or having built a competitive advantage, support arguments in favor of such a policy.

In contrast, policy path 2 can face substantial difficulties related to its implementation. A strong carbon price will be reflected in higher energy prices. Firms outside the EU competing in the same markets, but not being subject to (any or similarly high) carbon prices would benefit from their price systems not reflecting the full cost of environmental damage. This puts European products at a competitive disadvantage, at least in the short-run. Some sectors would be more affected than others, as will be the case for different EU Member States. ${ }^{4}$ Especially countries being specialized in carbonintensive products most likely will oppose a global strong carbon pricing scheme and will advocate exemptions for certain sectors or the free allocation of emission allowances to certain user groups, a scenario that is even more relevant with the current EU and financial crises raising the question whether such a policy would be affordable for all Member States. Hence, the incentives of policy makers might not be aligned with the optimal policy design from the society's perspectives, and this policy path would suffer from severe difficulties (a) to implement 'high-enough', adequate carbon price and (b) to include all GHG emissions into the scheme.

For policy path 3, there are barriers for implementation, as well. The definition of EU-level sectoral targets implies the determination of an optimal technology and innovation portfolio for the mid- and longer-term horizon and respective prioritization among sectors and research areas based on an advanced SET Plan. But such an optimal portfolio can only be determined under quite strong assumptions (all relevant information need to be available, functioning cross-sector and cross-country coordination). Moreover, the implementation of this policy would involve difficulties to agree on sectoral targets (e.g. different Member States might favor different technologies) and to agree on a burden sharing among Member States. It also has to be considered that regular (re-)negotiations would be necessary to adapt (EU-level and national) targets and research priorities. Member States also are typically reluctant to give too much power to the EU. According to Art. 194 of the TFEU, decisions regarding the energy mix of a country are a national issue and the definition of sectoral targets will cause problems related to the subsidiarity problem (see Box 1).

4 See Ellerman et al. (2010) for evidence on the past impact of the EU ETS on the competitiveness of different industries. See Delgado (2007) for a discussion on the impact of the EU ETS on different economies. 


\section{Box 1: Can the EU intervene on national energy mixes?}

According to Art. 194 (2) of the Treaty of the Functioning of the EU, being part of the Energy Title, EUlevel policy measures deemed necessary to achieve energy policy objectives such as the establishment of an internal market or supply security shall "not affect a Member State's right to determine the conditions for exploiting its energy resources, its choice between different energy sources and the general structure of its energy supply".

At the same time, Art. 192 (2)(c), being part of the Environment Title, establishes that environmental policy measures "significantly affecting a Member State's choice between different energy sources and the general structure of its energy supply" can be adopted. In this case, however, unanimity of the Council which actually allows every Member State to veto such decisions - and a consultation of the Parliament are required.

A centrally coordinated policy measure such as harmonized national targets for energy efficiency improvements or sectoral targets as introduced in policy option 3 would obviously affect Member States' choices of energy sources and structure of energy supply. Therefore, it only could be adopted under the environmental legal basis (referring to Art. 192) but would not be justified under the energy market provisions (as specified in Art. 194).

\subsection{Evaluation results}

The multi-criteria evaluation of the above policy paths for an EU energy technology policy illustrates that a prioritization of policies is not straightforward. No single policy is clearly superior to the others. Different policies perform best under different evaluation criteria. With respect to the different scenarios and technology mixes presented in the EU Energy Roadmap, policy path 2 probably could pave the way towards a 'diversified technology portfolio', whereas path 3 probably seems to be more suited for scenarios that need a stronger technology push, such as the 'high RES' or 'high energy efficiency' cases.

Different trade-offs arise regarding the choice of policies and instruments. Policy path 2 would allow for cost-efficient abatement given a perfect market setting but might be difficult to implement. Policy path 3 might be well suited to enhance green growth and can provide remedies to EU financial crises and institutional frictions, but suffers from weak carbon price signals and diluted technology targets. Besides the difficulty of evaluating impacts along one single criterion - various aspects and complexities have to be considered - alternative criteria can be weighted differently by different policy makers. Table 2 below summarizes our findings. 
Table 2: Summary of the evaluation of policy paths

\begin{tabular}{|l|l|}
\hline Criterion & Evaluation \\
\hline Climate-effectiveness & We assume that the decarbonization objective can be reached under all policies. \\
\hline Green growth & $\begin{array}{l}\text { Path 3 is most able to enhance green growth due to the strong role of directed } \\
\text { technology push and the possibility to explicitly support domestic European firms. } \\
\text { In contrast, path 1 has less ability to enhance green growth and path 2 has growth } \\
\text { potentials only in the longer-run, due to the high carbon price, which, however, also } \\
\text { attracts non-EU made abatement products. }\end{array}$ \\
\hline $\begin{array}{l}\text { Robustness to EU } \\
\text { financial crises and } \\
\text { institutional difficulties }\end{array}$ & $\begin{array}{l}\text { Path 3 is the most robust option with sectoral targets providing stable investment } \\
\text { signals. The ability to account for different national technology push programs and } \\
\text { to adjust the burden of decarbonization between Member States is only given in this } \\
\text { policy path. } \\
\text { In contrast, path 1 does not yet offer adequate solutions. Path 2 is not robust to } \\
\text { financial crises or institutional frictions due to the lack of the ability to account for } \\
\text { Member State heterogeneity. }\end{array}$ \\
\hline Cost-efficiency & $\begin{array}{l}\text { Path 2 is the most cost-efficient solution. Abatement costs across all sectors and } \\
\text { abatement channels are minimized when implementing one common emission } \\
\text { price. } \\
\text { In contrast, paths 1 and 3 suffer from weak carbon price signals. }\end{array}$ \\
\hline Implementability & $\begin{array}{l}\text { Path 1 is most easy to implement, as implementation efforts are low and } \\
\text { subsidiarity compatibility is given. } \\
\text { In contrast, path 2 is not fully feasible as the implementation of a scheme with one } \\
\text { unique and high enough carbon price covering all GHG emissions would pose sever } \\
\text { political difficulties. For path 3, implementation barriers mainly relate to achieving } \\
\text { an agreement on sectoral targets and the related burden sharing between Member } \\
\text { States. }\end{array}$ \\
\hline
\end{tabular}

\section{Policy implications for a revised SET Plan}

That each policy path has its own advantages and disadvantages suggests that on the way to 2050 policy paths might change. This notion stresses that a SET Plan should allow policymakers to act and foster decarbonization no matter what policy path prevails. In this sense, the policy context for a renewed post-2020 SET Plan and corresponding technology push is defined by market pull regimes, and here foremost by the EU ETS. Today, it can be heavily doubted that based on the current scheme and the currently determined emission cap, carbon prices in the magnitude of those reported in different EU Energy Roadmap scenarios and those needed in policy path 2 can be implemented. ${ }^{5}$ Though, design improvements have the potential to make the EU ETS a stronger policy instrument. The future ETS design should aim at including the highest possible base under the scheme and broaden the impact of the common carbon price, while also aligning non-ETS prices.

Given the current absence of a strong enough carbon price, together with the necessity to stimulate innovation today (see e.g. Aghion et al., 2009), the need for a renewed SET Plan with a higher signaling effect in terms of what technologies to push becomes apparent. Coming back to the discussion on the policy paths, with a highly volatile emission price, and a potentially asymmetric impact on different income classes and different income countries, the benefits of an ETS diminish, even though from a theoretical cost-efficiency point of view, a cap-and-trade carbon pricing scheme dominates policy alternatives such as technology targets. When re-thinking where to depart from current 2020 policies, it becomes clear that high carbon prices are promising for efficient

5 Carbon prices in the underlying simulation exercises are determined such that 2050 targets are reached, assuming equal prices/values for ETS and non-ETS sectors. These prices range between 234 and 310 EUR/t. 
decarbonization, but likely will not be entirely feasible for the foreseeable future. In such a policy context, the SET Plan and corresponding technology push gain in importance.

A renewed post-2020 SET Plan should allow for all possible future policy paths and not exclude the possibility to act within a certain future context. It should become a tool able to help policy makers in their policy making. Therefore, it should be more focused than the current SET Plan and provide the basis for planning and prioritization among decarbonization technologies. Similar to the current model, stakeholders from individual sectors could work together within Industrial Initiatives to identify technological progress and future research needs. In a second step, priority technologies - i.e. those (a) being key to achieve 2050, and/or (b) helping to support green growth within the Union should be identified based on a comprehensive approach across sectors. ${ }^{6}$ Selected technology targets and EU funding of innovation should then be in line with the SET Plan prioritization.

There are several reasons that justify some directed technology push, instead of building fully on technology-neutral support to innovation. First, certain low-carbon technologies are key to achieve the transition to a low-carbon economy and there are reasonable concerns that without such support they will not be developed and deployed at the necessary scale and/or on time. This could for instance be the case for CCS. All scenarios of the EU Energy Roadmap contain a substantial part of electricity generation using this technology (between 10\% in the 'high RES' and 33\% in the 'Reference' case in 2050) with CCS being viable from 2030 on. Other roadmaps present very similar numbers and assume commercial-scale deployment already for 2020 or 2025. However, as discussed elsewhere in-depth (e.g. Hirschhausen et al., 2010), CCS can only thrive, if at the same time financial, political and regulatory risks are reduced.

Second, European technology push can have its justification as a means to respond to fierce global competition in green-tech markets and to help to keep wealth within the Union. Whereas the burden to finance market pull measures always is with consumers and tax payers but benefits can be reaped by both domestic innovators and producers, but also market entrants from outside the EU, directed technology push can be designed such that it favors domestic players. Explicitly targeting specific technologies also allows policy makers to accelerate technology development and support industrial leadership. This strategy is promising especially for high-tech segments or parts of the value chain that cannot be outsourced to low-cost competitors. ${ }^{7}$ However, current trade disputes related to clean technologies illustrate the complexity of industry and trade policies, as recent plans by the EU to place tariffs on Chinese solar manufacturers show, see Bloomberg (2013). There is a fine line between supporting technologies and subsidizing industries. Any industrial or trade policy favoring European players, therefore, must be debated and designed with care and rationales for introducing such measures should only relate to environmental or innovation externalities.

Despite these advantages for a coordinated and centralized European technology push, the overall policy design should still rely to a large extent on bottom-up participation. Especially technology projects with 'normal risk and return profiles' are well suited to be supported by individual Member States, leaving high-risk support for the EU. While a bottom-up approach is certainly needed for national action plans and national funding, also the push coming from the European level will be bargained beforehand. Political considerations, such as who are beneficiaries of support, will

6 The current "business as usual" SET Plan does not include such a base for target setting across technology sectors in favor or against certain technologies. Hence, especially if carbon prices remain at relatively low levels, the current SET Plan is not able to deliver the basis for the then required strong target setting and corresponding technology push.

7 Regarding wind energy, for instance, top-European turbine manufacturers such as Vestas, Siemens, or Gamesa saw a continuous reduction in their global market share. But it is predominantly European manufacturers that are active in the offshore wind market today, and there could be an argument to use this advantage of being a pioneer, and to benefit from domestic technology adoption as well as from exporting the technology to non-European markets. 
aggravate the planning and priority setting for technologies when constructing the SET Plan and the agreements on where funding is derived from.

\section{Conclusion}

The EU commitment to achieve an almost entirely decarbonized European energy system by 2050 requires a stable long-term policy framework. Most current policy initiatives are running out in 2020, and clear guidance on the post-2020 policies to achieve decarbonization goals by 2050 is needed soon. To this end, this article develops and critically discusses three potential policy paths towards 2050 . Each path consists of different mixes of market pull and technology push instruments and different mixes of EU and Member State level governance. Whereas a first option relying on business-as-usual serves as a reference path, one alternative path relies on strong carbon price signals, while an opposing path relies on clear technology targets to foster the innovation in and deployment of low-carbon technologies. We find that that latter path has advantages in terms of political and institutional robustness and in terms of its ability to stimulate green growth. In contrast, the policy path relying on strong price signals could offer a cost-efficient solution.

Independently of the policy path realized, technology push has to be robust and to give clear signals to investors. For this sake we finally propose a design for a revised SET Plan that allows policy makers to push needed technologies within any future context. More specifically, while in its current design the SET Plan offers only limited ability to help achieve 2050 climate goals under low ETS prices, a renewed post-2020 SET Plan should entail the possibility for stronger technology targets. The technology targets can then aim at intermediate time horizons in 2030 or 2040 , and be renewed as technologies and carbon prices evolve towards 2050. Without such a tool able to support target setting based on a comprehensive approach across sectors, and with persisting low carbon prices, the achievement of the future decarbonization objective seems unlikely. 


\section{References}

Aghion, P., Hemous D., Veugelers R., 2009. No green growth without innovation. Bruegel Policy Brief 2009/07.

Baumol, W.J., Oates, W.E., 1971. The use of standards and prices for protection of the environment. Swedish Journal of Economics, 73(1), 42-54.

Bloomberg, 2013. EU said to plan duties up to $67.9 \%$ on China solar panels, bloomberg.com, May 9.

Delgado, J., 2007. Why Europe is not carbon competitive. Bruegel Policy Brief 2007/05.

EC, 2010. Energy 2020: A strategy for competitive, sustainable and secure energy. COM(2010) 639/3.

EC, 2011. A roadmap for moving to a competitive low-carbon economy in 2050. COM(2011) 112.

EC, 2011b. Renewable energy: Progressing towards the 2020 target. COM(2011) 31.

EC, 2011c. European competitiveness report 2011. SEC(2011) 1188.

EC, 2012. A European strategy for Key Enabling Technologies: A bridge to growth and jobs. $\operatorname{COM}(2012) 341$.

EC, 2012b. Renewable Energy: A major player in the European energy market. COM(2012) 271.

EC, 2013. Energy Technologies and Innovation. COM(2013)253.

Ecofys, Fraunhofer ISI, EEG and LEI, 2011. Renewable energy policy country profiles. 2011 version. Report prepared within the Intelligent Energy Europe project RE-Shaping - Shaping an effective and efficient European renewable energy market.

European Parliament, 2010. Report on simplifying the implementation of the Research Framework Programmes. A7-0274/2010.

Ellerman, A.D., Buchner, B.K., 2008. Over-allocation or abatement? A preliminary analysis of the EU ETS based on the 2005-06 emissions. Environmental Resource Economics, 41(2), 267-87.

Ellerman, A.D., Convery, F.J., de Perthuis, C. de, 2010. Pricing carbon: The European Union emission trading scheme. Cambridge University Press, Cambridge.

Eurelectric, 2011. Power Choices: Pathways to carbon-neutral electricity in Europe by 2050.

Foxon, T.J., 2003. Inducing Innovation for a Low-Carbon Future: Drivers, Barriers and Policies. Report for The Carbon Trust.

Gilder-Cooke, S.v., 2012. Will austerity derail Europe's clean-energy movement? Article published at http://www.time.com.

Goulder, L.H., Parry, F.J., 2008. Instrument Choice in Environmental Policy. Review of Environmental Economics and Policy, 29(2), 152-74.

Grubb, M., 2004. Technology innovation and climate change policy: An overview of issues and options. Keio Economic Studies, 41(2), 103-32.

Hirschhausen, C.v., Haftendorn, C., Herold, J., Holz, F., Neumann, A., Ruester, S., 2010. Europe's coal supply security: Obstacles to carbon capture, transport and storage. CEPS Policy Brief 223/2010.

Horbach, J., 2007. Determinants of environmental innovation: New evidence from German panel data sources. Research Policy, 37(1), 163-73.

Hyytinen, A., Toivanen, O., 2005. Do financial constraints hold back innovation and growth? Evidence on the role of public policy. Research Policy, 34(9), 1385-403. 
International Energy Agency, 2012. Energy Technology Perspectives 2012 - Pathways to a clean energy system.

Jacobsson, S., Bergek, A., Finon, D., Lauber, V., Mitchell, C., Toke, D., Verbruggen, A., 2009. EU renewable energy support policy: Faith or facts? Energy Policy, 37(6), 2143-6.

Jaffe, A.B., 1996. The importance of spillovers in the policy mission of the Advanced Technology Program. Journal of Technology Transfer, 23(2), 11-9.

Johnstone, N., Hascic, I., 2010. Directing technological change while reducing the risk of (not) picking winners: The case of renewable energy. Working Paper, mimeo.

Jones, C., Glachant, J.-M., 2010. Why and how the EU can get a (near to) carbon-free energy system in 2050. MIT CEEPR Working Paper 10-002.

Kitzing, L., Mitchell, C., Morthorst, P.E., 2012. Renewable energy policies in Europe: Converging or diverging? Energy Policy, 51(12), 192-201.

Martin, S., Scott, J.T., 2000. The Nature of Innovation Market Failure and the Design of Public Support for Private Innovation. Research Policy, 29(4-5), 437-47.

Martin, R., Muuls, M., Wagner, U., 2012. An evidence review of the EU ETS, focusing on effectiveness of the system in driving industrial abatement. Report prepared for the Department of Energy and Climate Change.

Murphy, L.M., Edwards, P.L., 2003. Bridging the valley of death: Transitioning from public to private sector financing. National Renewable Energy Laboratory, Working Paper NREL/MP-720-34036.

Nemet, G.F., 2009. Demand-pull, technology-push, and government-led incentives for nonincremental technical change. Research Policy, 38(5), 700-9.

Olmos, L., Ruester, S., Liong, S.J., 2012. On the selection of financing instruments to push the development of new technologies: Application to clean energy technologies. Energy Policy, 43(4), 252-66.

Ragwitz M., et al., 2011. Review report on support schemes for renewable electricity and heating in Europe. Report prepared within the Intelligent Energy Europe project RE-Shaping - Shaping an effective and efficient European renewable energy market. 


\section{Author contacts}

Sophia Ruester (Corresponding author), Sebastian Schwenen and Jean-Michel Glachant

Florence School of Regulation

Robert Schuman Centre for Advanced Studies, EUI

Via Boccaccio 151

50133 Firenze

Italy

Email: sophia.ruester@eui.eu

\section{Matthias Finger}

École Polytechnique Fédérale de Lausanne

Station 5 (ODY 3.03)

1015 Lausanne

Switzerland 